\title{
Didactic Engineering for the Treatment of Variation of Functions in Pre-University Level: The Increasing and Decreasing Cases
}

\author{
Noé Oswaldo Cabañas Ramírez ${ }^{1 \star}$, Edgardo Locia Espinoza ${ }^{1}$, Armando Morales Carballo ${ }^{1}$, Héctor Merino Cruz ${ }^{1}$
}

${ }^{1}$ Autonomous University of Guerrero, MEXICO

*Corresponding Author: noe_ocr@hotmail.com

Citation: Cabañas-Ramírez NO, Locia-Espinoza E, Morales-Carballo A, Merino-Cruz H. (2020). Didactic Engineering for the Treatment of Variation of Functions in Pre-University Level: The Increasing and Decreasing Cases. Pedagogical Research, 5(2), em0055. https://doi.org/10.29333/pr/7846

ARTICLE INFO

Received: 26 Feb. 2020

Accepted: 28 Feb. 2020

\begin{abstract}
This paper reports the results of the experimentation of a didactic engineering for the treatment of the sense of variation of functions with pre-university students. The theoretical references of the investigation are grounded in the theory of didactic situations and the methodological elements in the didactic engineering, the use of counterexample and the didactic strategy known as Scientific Debate in Mathematics Courses. As a result of the experiment, it was identified that the methodological resource allowed the students to develop construction processes of the concepts of increasing and decreasing functions; the dynamic context fostered intuitive ideas of increment and decrement, and intuition about the conditions involved; the debate and counterexample on the graphic and algebraic treatments allowed the establishment of the conditions that structure the formal definition of these concepts.
\end{abstract}

Keywords: didactic engineering, sense of variation of a function, scientific debate in mathematics courses, counterexample

\section{INTRODUCTION}

The study of variation of functions is a mandatory content in middle-high school plans and curricula, specifically in Mexico. The learning of this content is consolidated throughout the studies at this level, because it is an integrative content where the main concepts of differential calculus converge and are needed; therefore, the study of variation of functions may be an opportunity to strengthen the maturity of the mathematical reasoning in students for the formulation of conjectures, inductive processes, argumentation, validation and refutation of theorems related to this mathematical concept, if it is not only treated as a set of recipes or algorithms. The analysis of functions will be understand as the study of the sense of variation (growth and decrement) of a function, the determination of the intervals of concavity and convexity, inflection points, extremum (maximum and minimum), and vertical, horizontal or oblique asymptotes (Leithold, 1992; Piskunov, 2018; Stewart, 2007; Swokowski, 1982).

Several studies that focused on the analysis of the teaching and learning processes of calculus report that middle and college students present several difficulties in a procedural level such as studying the sign of the derivative of a function, linking the sense of variation of a function and the sign of its derivative, or reading and interpreting a result on a graph. In the conceptual level, they have problems understanding the basic concepts of calculus, such as the concept of function, growth and decrement, maxima and minima, (Castillo, 2009; Cuevas \& Delgado, 2016; Delgado, 2013; Díaz, 2009; Pineda, 2013; Reséndiz, 2006; Rubí, Moreno, Pou, \& Jordán, 2010; Ruiz, Hernández, \& Gutiérrez, 2015; Salinas \& Alanís, 2009; Zúñiga, 2009).

The identification of this problem motivated several investigations with different theoretical and methodological references to study the sense of variation of a function (Díaz, 2009; Engler, Vrancken, Gregorini, Müller, Hecklein \& Henzenn, 2008; Rey Cabrera, 2016; Zúñiga, 2009). The results of these investigations indicate that both, teachers and students, have difficulties in understanding and using this content. For example, the study of Valero (2003), conducted with students, identified seven alternative conceptions of the sense of variation of functions. The most common conceptions and resistant to change are: the conception that a function has negative image only if it is decreasing, a function is increasing if its graph goes up, without any coordination between changes in the abscissa and in the ordinates, and a function is decreasing if its graph goes down.

Some possible reasons for the difficulties reported by research in teaching and learning the fundamental concepts of calculus could be: it has been commonly identified that students in their first courses of calculus do not develop enough knowledge of these concepts; they use certain schemes or conceptions which have been mentally constructed from the teachings of their teachers and the influence of textbooks instead of making use of formal definitions. In addition, traditional teaching tends to overestimate algorithmic processes where rote learning method and expositions delay the student's learning of mathematical 
thought, specifically on the topics mentioned. In order to contribute to the teaching and learning of the fundamental concepts of calculus and their usefulness in the analysis of the sense of variation of the functions of real variable, the following problem was addressed: How can the processes of teaching and learning of the sense of variation of a function at the pre-university level be encouraged?

\section{THEORETICAL BACKGROUND}

The theory of Didactic Situations of Brousseau (1978) establishes the possibility that the student's construction of knowledge is based on adaptations and interactions with a didactic medium where such knowledge is built. The main actors in this activity are the student, the teacher, and the mathematical knowledge.

Brousseau considers the design of didactic situations that include a set of activities established explicitly or implicitly between a pupil, a group of students, a specific medium (which eventually includes instruments or objects), and an educational system (represented by the teacher) with the aim to ensure the student's appropriation of an established knowledge or a knowledge that is in the process of being established. The goal is that the class becomes a micro-scientific community, where knowledge is built as a necessary tool to overcome the epistemological, didactic and cognitive obstacles identified in the mathematical content at play, identifying the different a-didactic and didactic stages; which are fundamental in the construction of knowledge, according to this theory. The a-didactic stage is where knowledge is constructed through the interaction of the student with the didactic environment without the intervention of the teacher; the didactic stage are the situations of action, formulation, validation and institutionalization. The intention of the micro-scientific communities formed in class is that the students build their mathematical knowledge, fostering the dialectical interaction between proofs and refutations, examples and counterexamples, underlining the importance of the argumentations on their first ideas for the proof of conjectures to make progress in the mathematical discovery described by Lakatos (1976).

\section{Use of Counterexamples}

Several investigators (García \& Morales, 2013; Hernández, Locia, Morales \& Sigarreta, 2019; Klymchuk, 2012; Morales, Locia, Ramírez, Sigarreta \& Mederos, 2018; Zazkis \& Chernoff, 2008) agreed that the formulation of conjectures and the use of counterexamples allow students to think about the how and why of the processes used to reach conclusions, and to reduce the algorithmic and rote learning procedures; they also enable progress in the structuring of the necessary logical-mathematical reasoning of students, so they can be valued and improved by the teacher and the students. In this way, their reasoning can be refined or even strengthen, which, in turn, can allow the formation of a critical and analytical thought, essential to form individuals in a society. It also allows changing the naïve thoughts of students, specifically the inadequate perceptions that cause limitations in their understanding of a mathematical concept and become a cognitive obstacle that prevents any progress in the structuring of a mathematical thought, make students think about some mathematical aspects that have never been thought of before, open their eyes to the importance of the conditions of rules, theorems and properties of mathematical objects, reveal erroneous concepts and force them to pay attention to each detail improving the comprehension of the mathematical concepts.

\section{Scientific Debate in Mathematical Courses}

Consistent with the Theory of Situations, Legrand (1993) states that a student actually enters in the scientific game when he becomes aware of scientific intuitions, takes mathematical attitudes, or generates ideas that come through when analyzing a problem producing counterexamples and the necessary argumentations that lead to the solution of the problem. According to Legrand, the ideal way to achieve this type of circumstances is that teachers introduce students to problematic situations designed for this purpose, or by conjectures or counterexamples that students bring to class. This didactic strategy is called "the scientific debate in mathematics courses."

The goal of the scientific debate in mathematical courses is not to discover original properties, but to discover the meaning of the mathematical results and to appropriate the reasoning methods. It is about allowing students to turn to scientific issues, trying to avoid distorting the sense of the knowledge learned and finally reaching a certain form of autonomy of thought. The subjects of the debate revolve around the essence of theorems and definitions, considering three parts in a scientific debate: In the first part, the teacher provokes and organizes the students' production of statements of scientific character in different ways; in the second part, these statements are submitted to the reflection and discussion of the students who must pronounce on their validity and, in the third part, the statements that were validated in classroom by a demonstration take the character of theorem or definition.

The role of students-mathematicians in a scientific debate will be to produce precise counterexamples and to provide arguments recognized by the whole mini-scientific community formed in the classroom; validation will be carried out by the teacher who must establish that he has the necessary knowledge of the topic in question. As students identify this type of didactics, they will be in a position to accept or discard the theorems generated by their argumentations, considering the principle or law of the counterexample which states that: "one counterexample is enough to proof the falseness of a conjecture of universal character." 


\section{METHODOLOGY}

Didactic engineering (DE) of Artigue (1995) is the methodology used in this research. It assigns a specific function to the investigations according to the four phases that make it up. Phase 1: preliminary analysis; phase 2: conception and a priori analysis phase 3: experimentation, and phase 4: a posteriori analysis and evaluation. The main goal is to provide the teacher with working tools in the production of knowledge, focusing on modeling teaching-learning situations. The fundamental characteristic of $D E$ is the confrontation between the a priori analysis and the a posteriori analysis about the reality observed during its implementation in classroom.

\section{Preliminary Analysis}

The preliminary analysis (epistemological, didactic and cognitive) was obtained in Cabañas-Ramírez, Locia-Espinoza and Morales-Carballo (2020).

The preliminary analysis shows the need for the treatment of the sense of variation of a function (increasing and decreasing functions), because the epistemological report identified the existence of two approaches in the evolution of the concept of the sense of variation: the intuitive dynamic approach (a variation associated with two quantities in which, if one increases the other also increases or decreases, depending if the function is increasing or decreasing) and the static approach (an application between two ordered sets that preserve or invert the order).

Currently, the definition of function and associated concepts that help to understand its sense of variation are presented under the static approach, which has implications in the processes of understanding. The didactic and cognitive analysis shows that, at most, the texts only address the intuitive notion of the sense of variation without considering the notion of preservation or inversion of order or the formulation of the definition. Therefore, a strategy is necessary to form and transit or to develop the purely intuitive comprehension of the sense of variation to conform the notion underlying the formal definitions of an increasing and decreasing function, and the formulation of the definition itself.

\section{Conception and a Priori Analysis}

Three activities were developed considering the results obtained in the preliminary analysis and the report of the investigations that describe the teaching and learning problems of the fundamental concepts of calculus associated with the sense of variation of a function. The intention of the implementation of these activities was to encourage the construction of the definitions of increasing and decreasing functions by undergraduate students.

The dynamics of implementation considered five teams of five or six students who solved the designed activities interacting first among each other, and later with other teams seeking to validate and institutionalize their results through the use of counterexamples in the scientific debate constituted in the classroom.

Activity I. Emergence of arguments in the sense of variation.

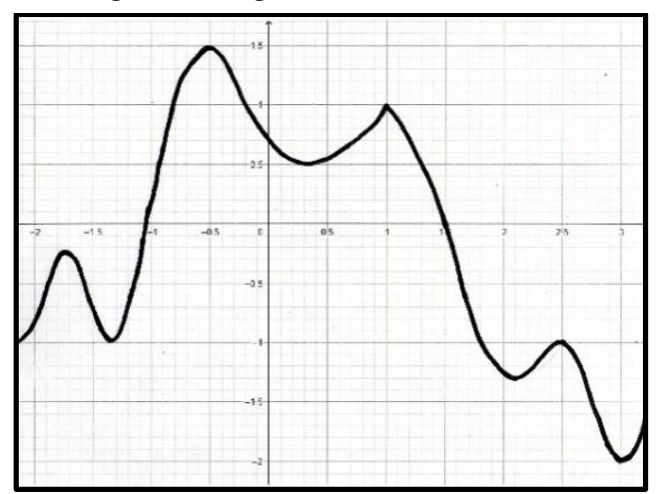

a) Curve presented to the first transmitters.

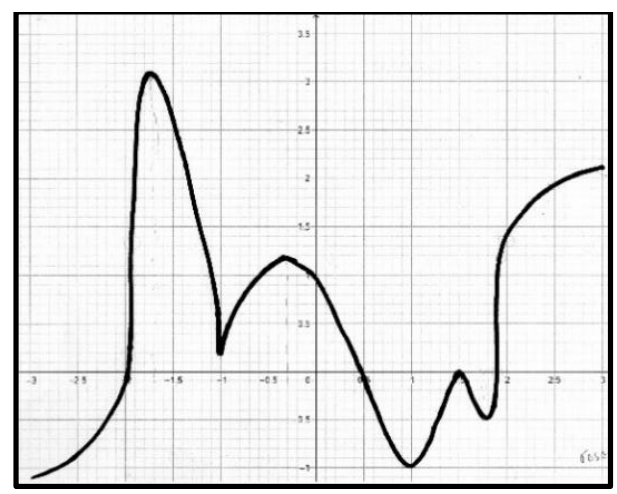

b) Curve presented to the second transmitters.

Figure 1. Graphic representations delivered to teams. Source: Own creation.

This activity was carried out in teams of five or six members. The purpose is to cause the emergence of concepts and arguments associated with the sense of variation of a function in an intuitive way and with natural language. This is a first stage in the formation of the intuitive notion. For this purpose, we consider the following:

The person in charge of the experimentation (teacher) establishes that the teams would be subdivided and form pairs of teams (transmitter/receiver) and work this activity as described below:

a) The transmitters receive the graph of a curve (Figure 1, a). They make a list describing the behavior of the assigned graph: domain, image, zeros of a function, continuity, intervals of growth and decrease, relative and global maximum and minimum, inflection points, convexity, and concavity, among others (even when the students are not expected to use this language).

b) The transmitters send the list to the receivers. The receivers build a graph that meets the given conditions taking into account the information received. Finally, the given instructions and its representations are discussed. Similarly, the activity is repeated exchanging the roles of the transmitters with the receivers and vice versa, only changing the graph studied (Figure 1, b). 
The didactic variable identified is the level of reading that is made from the graphs, influencing the argumentation processes that students emit to transmit ideas such as: growth, decrement, maximum and minimum, domain and codomain, among others.

Activity II. The sense of variation conditioned by the independent variable.

Figure 2 represents a square $A B C D$ of side $8 \mathrm{~cm}$, in which an isosceles triangle AIM and a square MGHB were drawn. The isosceles triangle has the segment $A M$ as its base, with $M$ moving along the segment $A B$, and the height equal to the side of the square.



Figure 2. Geometric representation of a phenomenon of variation, object of study. Source: Own creation.

1. Investigate the position of the point $M$ in segment $A B$ so that the area of the isosceles triangle is equal to $6 \mathrm{~cm}^{2}$ and $8 \mathrm{~cm}^{2}$. Give arguments for each case.

2. Is it possible that the area of the triangle equals the area of the square? Argue your answer.

3. How does the area of each of the three figures change as long as $M$ moves from left to right? And from right to left?

The development of this activity will make it possible to show that the sense of variation of a function depends on the relationship between the independent and dependent variable (linked variables), so that, changes in the first variable have consequences in the sense of variation.

The didactic variable of this second activity is the implications of the variation of the point $M$ along the length of the segment $A B$ o vice versa. This influence the construction and interpretation of the mathematical model of increasing or decreasing functions. 
Activity III. Towards the definitions of increasing and decreasing functions.

Answer the following questions:

Exercise 1. Let $f(x)$ be a function whose variations are described next:

- $f(-20)=1$

- $f$ is increasing in the interval $[-20,-3]$

- $f(-3)=5$

- $f$ is decreasing in the interval $[-3,1]$

- $f(-1)=0$ y $f(1)=-3$

- $f$ is increasing in the interval $[1,4]$

- $f(4)=0$

1. What are the values among which $f$ is found in each of the following cases?
a) When $x$ is between -3 and -1
b) When $x$ is between 1 and 4
c) When $x$ is between -3 and 4

2. Compare the following images whenever it is possible
a) $f(-5)$ and $f(2)$
b) $f(-4)$ and $f(0)$
c) $f(-2)$ and $f(5)$
d) $f(7)$ and $f(-3)$

Exercise 2: Let $f$ be a function that satisfies the following conditions:

- $f(-5)=3, f(-2)=0$ and $f(0.5)=3, f(3)=-1$

- It is decreasing in the intervals $[-5,-2]$ and $[0.5,3]$ and increasing in the interval $[-2,0.5]$

1. Draw the corresponding graph

2. Locate the extreme points

3. Place the symbols $<$ or $>$, as appropriate in the following images
a) $f(-4) f(-3)$
b) $f(1) f(2) f(3)$
c) $f(-2) f(-1.99) f(-1.9)$
d) $f(-4) f(-1) f(1)$

Exercise 3: Let $f$ be a function with domain $[-5,4]$. It is known that $f$ is an increasing function in the intervals $[-3,-1]$, and $[3,4]$, a decreasing in the intervals $[-5,-3]$ and constant in the interval $[-1,3]$.

It is also known that $f(-5)=4, f(-3)=-1, f(-1)=1$ and $f(4)=3$.

1. Compare $f(0)$ and $f(2)$, justify your answer.

2. Compare the images of $f$ at -2 and -1.5 , justify your answer.

3. Plot a possible curve for the function $f$.

Exercise 4. Let $f$ be a function whose variations are described in the following way:

- It is an increasing function in the intervals $[-8,-5]$ and $[-1,-2]$, and decreasing in $[-3,-1]$

- $f(-8)=-1, f(-5)=4, f(-3)=4, f(-1)=-3$, and $f(2)=-1$.

1. Give the domain of the function.

2. Propose four strictly positive real numbers with the same order as their images for $f$

3. Propose four real numbers ordered in the reverse order respect to their images for $f$.

4. Propose four real numbers whose images for $f$ are equal.

Exercise 5: Plot a curve that represents the function $f$ knowing that:

- Its domain is $[0,5]$

- $f$ is increasing and negative in that interval

Exercise 6: Plot a curve that represent a function $f$ knowing that:

- Its domain is $[-5,4]$

- $f$ is increasing and negative on $[-5,1]$ and decreasing an negative on $(1,4]$

Exercise 7: Plot a possible graph for the function $f$ in each of the following items and answer the questions:

a) $f$ is a function whose domain is $[-5,5]$ and it is known that $f(-5) \leq f(-4.99) \leq f(-4.98) \leq f(-4.97) \leq \cdots \leq f(4.97) \leq f(4.98) \leq f(4.99) \leq f(5)$,

What can be said about the sense of variation of $f$ ?

b) The same question for the function $f$ that satisfies

$$
f(5) \leq f(4.99) \leq f(4.98) \leq f(4.97) \ldots \leq f(-4.97) \leq f(-4.98) \leq f(-4.99) \leq f(-5)
$$

The aim of this activity is, first, to train students in the notion of an increasing (or decreasing) function as an application between two ordered sets which preserves (or reverses) the order and, subsequently, to construct the respective definitions, making use of the concepts achieved in activities I and II. The students will identify the essential characteristics of the notions of increasing and decreasing functions by dealing with the exercises of this activity, namely the fact that an increasing function preserves the order and that a decreasing function reverses it; they will also express these characteristics in terms of logical 
implications and the need to use universal quantifiers in the formulation of the definition. Of course, these approaches will be attained depending on the success of the students in the first activities. Methodologically speaking, according to the moments of the $\mathrm{DE}$, this is when the development of counterexamples in the scientific debate that is taking place becomes very important.

The didactic variable in this activity consists in the choice of the variables of the domain and its images for comparison. As a result of comparison and interpretation, it is expected that the flow of information will influence the cognition of the axiomatic building of students in the construction of the definitions of increasing and decreasing functions.

\section{Experimentation}

The experiment was carried out with 31 students of the Bachelor of Mathematics degree of the Autonomous University of Guerrero, Mexico. At that time, the students were enrolled in their first semester, and were studying the compulsory learning unit Pre-Calculus, which is taught 5 hours a week. Considering the group as a whole, the experimental population was heterogeneous in terms of knowledge. The written productions of the students and video recordings during the treatment of the activities were considered as evidences. Dynamic of work: Five teams between five and six members were formed; the activities were developed one at a time, seeking not to influence the preparation of the responses of the students. The activities were implemented in six sessions of 90 minutes each, and were coordinated by a person in charge of the experimentation.

The following moments were considered in the process of developing the activities: First: The teams are formed and the person in charge of the experimentation gives the instructions, second: selected students of each team present the results of their work, and third: a joint activity is carried out between the person in charge of the experimentation and the students community where the formulations of the teams emerge and are discussed through scientific debate. These moments lead to the activity of institutionalization.

The activities were structured as follows: Activity I: Emergence of arguments of sense of variation. It consists of one exercise with two different options; one was directed to the transmitters and the other to the receivers. It was carried out in sessions one and two. Activity II: The sense of variation is conditioned by the independent variable. It consists of one exercise with three questions, and it was carried out in sessions three and four. Activity III: Towards the definitions of increasing and decreasing functions. It consists of seven exercises and was carried out in sessions five and six.

The role of the person in charge of the experimentations was to coordinate, introduce and conduct the debate to institutionalize knowledge about the definitions of increasing and decreasing functions.

\section{A Posteriori Analysis and Assessment}

The data analysis took place after the activities were carried out. This analysis incorporated: (a) the elements of the sense of variation, increasing and decreasing functions, that appeared in both written and audio productions, and (b) strategies of solution used by the students to transmit information. In these productions, we identify the effect of attention to the phases of action, formulation, validation and institutionalization established by the theory in the treatment of activities.

\section{Activity I}

Table 1 describes the productions of the students in the phases of action and formulation. The column named Strategy indicates the type of strategy used by the students, and the column Description describes and analyzes the intuitive ideas about the definitions of increasing and decreasing functions.

Table 1. Strategies identified in the productions of the students

\begin{tabular}{ll}
\hline Strategy & DESCRIPTION AND ANALYSIS \\
\hline Simple tabulation & $\begin{array}{l}\text { Three receiving teams used this strategy; they drew up a table with values 'x' and 'y' obtained from the graph. These } \\
\text { teams located several points of the given graph, in particular, those points of the curve that match the nodes of the } \\
\text { reticule or whose abscissas are very close (to have a "large" of them). }\end{array}$ \\
\hline $\begin{array}{l}\text { Tabulation plus } \\
\text { dissection }\end{array}$ & $\begin{array}{l}\text { Three sub-teams used this strategy. These teams drew up a table, and, in addition, dissected the graph considering the } \\
\text { curve in "parabolic" pieces. Therefore, they located points at the beginning of each "parabola", in the middle (referring } \\
\text { to the maximum or minimum of the parabola), and at the end. Their instructions indicated the appearance of the graph, } \\
\text { using terms such as: parabola that opens up or down, vertex, "pieces of circumference", "connect points not in a straight } \\
\text { line", and obtain soft curves, among others. They also used terms of natural language, such as "mountains" or "hills". } \\
\text { They also located intersections with the axes. }\end{array}$ \\
\hline $\begin{array}{l}\text { Dissection plus } \\
\text { extreme points }\end{array}$ & $\begin{array}{l}\text { Three sub-teams used this strategy. It consisted on locating first the extreme points of the curve (maxima and minima) } \\
\text { and dissecting it in regions that go from one extreme point to the next one (from left to right), and locating points of the } \\
\text { curve in each region. They located the intersections with the axes as additional information. }\end{array}$ \\
\hline $\begin{array}{l}\text { Dissection plus a } \\
\text { sense of variation }\end{array}$ & $\begin{array}{l}\text { Only one sub-team used this strategy. The students located the coordinates of the extreme points, and dissected the } \\
\text { variation such as: "the curve goes up" or "the curve goes down", to specify the behavior in each region identified, so the } \\
\text { receiving team gets a graph that was very close to the original one. }\end{array}$ \\
\hline
\end{tabular}

The coincidences found in the four strategies referred to reading the graph from left to right while studying the graphic behavior, using intuitive ideas to explain the behavior and comparing segments of curves with "parabolas", "semi parabolas", "circumferences" and using terms like "hills", "mountains", and "waves", among others. Only one team used terms that referred to the sense of variation of functions. These productions helped the person in charge of the experimentation to lead to institutionalization, promote scientific debate and develop the definitions.

The discussion began with the expositions of the instructions given by each transmitter team and the graph produced by the receivers, and then compared the effectiveness of each strategy. The students quickly realized that the strategies of simple 
tabulation (1) and dissection plus a sense of variation (4) led to graphs that were more similar to the original one. However, strategy 4 is more economical, because it requires fewer instructions than the first one. The debate was then directed to reach a consensus on the terminology of increasing or decreasing functions.

TEACHER: Let us analyze the behavior of the curve. In this case, you say that it is going up, in this way [He moves his hand following the trajectory of the graph projected on the blackboard. See Figure 1, a], then it goes down, and then goes up.

Student 2(S2): This means that it increases, then decreases, and then it increases again.

TEACHER: How would it be here?

E2: It increases there.

TEACHER: Increases. [The TEACHER highlights the term expressed by S2]

S2: And then it decreases.

S1: And what is the name of this?

TEACHER: What is the name? Well, increasing and decreasing. It is said that in these parts [points out the graph again] the function is increasing, and in these other parts, the function is decreasing.

The emergence in the context of these two terms (up/down) was expected in this first phase using the common language of the students; later, the standardized language (increasing/decreasing) would be achieved during the institutionalization phase through the debate set up in the classroom.

\section{Activity II}

A common procedure was identified by all teams. It consists of the following steps: (1) analysis of the given geometric figures, (2) construction of algebraic expressions that model the situation, (3) drawing up a table, (4) establishing a direction (from left to right), and (5) plotting and interpreting the data obtained to answer the three questions of the instrument.

The debate started with the exposition of the productions of the students (algebraic expressions, tables, graphic representations, and the answer to each question). The TEACHER questioned the students about the graphs.

TEACHER: How did you get these graphs? [...], could you explain what variables did you choose for these functions? [...] [The teacher points out Figure 2 and the graphs shown by the students].

The following paragraph shows the answer to these questions presented by S1 to his classmates:

S1: Well, for the area of the triangle we looked for the base and the height; we realized that the segment here was the base and all this was the height [points out the figure of the activity]. We also realized that this segment was the large segment minus this segment, then it is 8 minus this segment, minus $l$, where $l$ is the segment in here, so it is $8-l$. Then, we figured out that the length of the height should also be $l$, because it was one side of the square, and its value was supposed to be $l$, so we called it $l$. Then, the area depends on this side, on how this side was varying [considering the base of the square as the independent variable]. We figured out that it was a value that was first increasing, and then it decreases again. The area of the square was only a function of $l$, it was really simple.

Student(S4) answers these questions:

S4: Well, we observed that the area of the square is $8 \times 8$, then we started moving the point $M$ from the point $A$ and called the value $x$, and since this is a square, I have to move the same over here, so this is also $x$, the height of our triangle. Therefore, it was going to be $8-x$, and as the base of the triangle is $x$, the square will be moving as $x$ moves [referring to taking the base of the triangle as the independent variable].

The following transcription describes the debate, where the TEACHER confronts the teams expressing "I suppose that you found exactly the same values in the first two questions that were asked to team 1". S4 begins to associate the displacements of $M$, with respect to the base of the triangle and the square, and the graph obtained. So, the TEACHER asked another question that triggered the analysis of the reasons to obtain different answers for the same question:

TEACHER: And how did you find it? Tell me where the 5.33 comes from. Read the questions again.

Student 5(S5): I believe that the difference is that we took $x$, the value that we consider to give values, and my classmates considered the other part. So, 5.33 is what we needed to get this, and 5.33 and the point 2.66 , their sum is 8 , and that is the difference.

TEACHER: Let's see, 5.33 plus 2.66 equals to... 
S5: Ok, I think 2.66 is periodic, isn't it?

S1: Eh... yes

S5: And our 5.33 is periodic, then the sum of both numbers is 8 and that is the difference; they considered this part [points out the base of the square] to give values, this part, and we considered this other part [points out the base of the triangle].

It was observed that the intention of the students was to associate the numerical value obtained by the teams of S5 and S1. S5 used the analysis to deduce that the sum of these two values (taken from left to right and vice versa) is the same as the side of the square $A B C D$. After identifying the meaning and relation of dependence between these two variables, she looked for the relationship between these situations and the graph obtained (see Figure 3 ).

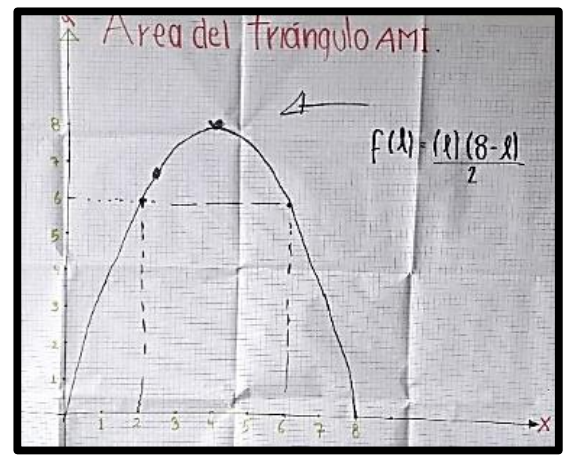

a) Variation of the area of the isosceles triangle.

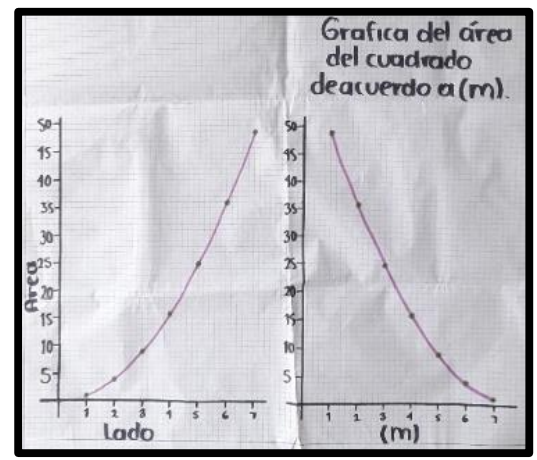

b) Variation of the area of the square.

Figure 3. Graphical representation of the variations of the study phenomena

The intervention of the TEACHER is in the sense of establishing similarities between the results of the teams. From this intervention, the team of S5 managed to express clearly that the sense of variation obtained depends on the choice made of the independent variable (the segments $A M$ or $M B$ ), see Figure 4.

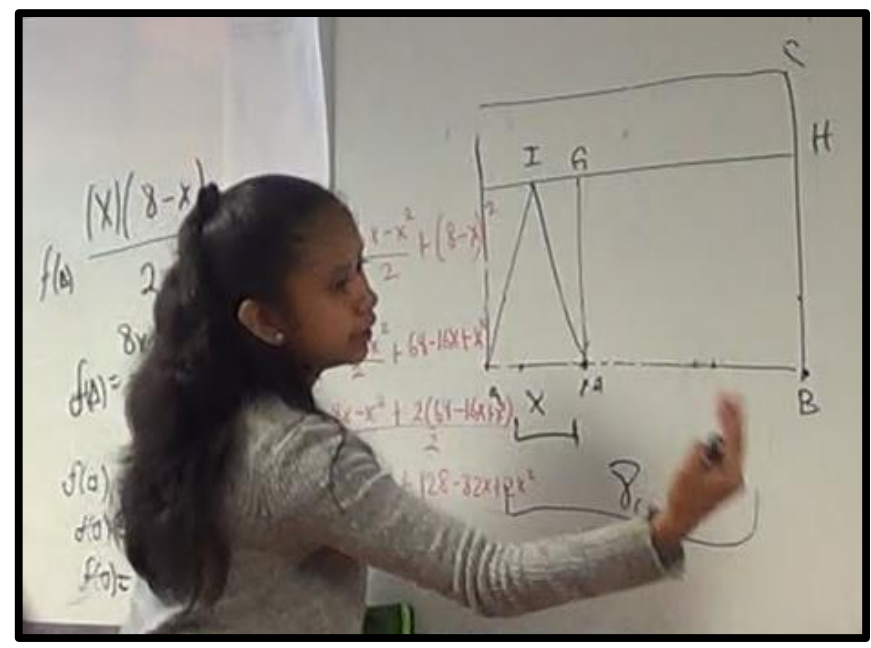

Figure 4. Student S5 during the analysis of the approach of the TEACHER

TEACHER: Very well, you can see it is relative, the choice could have been made in two ways. In fact, team 1 and 2 obtained exactly the same graph, and so did your team. Student 6 (S6), right? You got exactly the same as the team of S1, but others also got a decreasing function.

S5: Their movement was from here to here, they used this [right to left]. Then when its value is 0 , I suppose that it is here, and we began from the moment when M starts moving from this point to this other [left to right], so when the value of $x$ is zero, our square should have an area of 64 . This is why there is a difference in the graphs.

TEACHER: The graphs are different, so who is right then

S5: Both.

TEACHER: Both, exactly.

S5: One is when $M$ goes from here to here [points out the base of the triangle moving from left to right] and the other is from here to here [points out the base of the square from right to left] (See Figure 4). 
The students managed to identify and communicate the relationship between the independent and dependent variables according to the stated goal, because they expressed that the variation will depend on the direction in which the independent variable is chosen (from left to right or vice versa). Finally, the TEACHER returned to what the students expressed (described in the former lines) during the institutionalization and allow them to move towards the formalization of the definition of increasing and decreasing functions, as identified in the following production:

TEACHER: We obtained different things when the point $M$ moves from left to right or when it moves from right to left, it depends on the movement we consider. So, the issue of an increasing or decreasing function depends on how the independent variable is moving [...]

TEACHER: The property of a function of being increasing or decreasing is called sense of variation. We will refer to this when we talk about the sense of variation; that is, in the first case, we have that the sense of variation is decreasing in the graph on top [points out the graph of the area of the decreasing square elaborated by two teams]; while the sense of variation of the graph of the area of the square of team 1 [increasing graph of the area of the square] is increasing.

It is important to remind that the terms increasing and decreasing emerged in activity I, so it was possible to use these arguments in the productions of the students in activity II. In this regard, they identified that "when the point $M$ moves from left to right, the function that represents the area of the square has a decreasing sense of variation, while the function that represents the area of the triangle has an increasing sense of variation reaching the maximum value at 4 units, and then the sense of variation is decreasing. Similarly, when the point $M$ moves from right to left, the behavior of the function that represents the area of the square has an increasing sense of variation, and the function that represents the area of the triangle is increasing until it reaches the maximum value at 4 units and then it decreases."

\section{Activity III}

The first exercises of this activity provide information on the sense of variation of the function. Considering this information, the students are asked to sort the images of specific points; in some cases, the given information was not enough to compare these images. The intention is that the students analyze and identify implications of the type " $a<b<c<\cdots<d$ implies that $f(a) \leq f(b) \leq f(c) \leq \cdots \leq f(d)$ " for increasing functions, and of the type " $a<b<c<\cdots<d$ implies that $f(a) \geq f(b) \geq$ $f(c) \geq \cdots \geq f(d)$ " for decreasing functions to build implications of the type $x_{\alpha}<x_{\beta} \Rightarrow f\left(x_{\alpha}\right) \leq f\left(x_{\beta}\right)$ and $x_{\alpha}<x_{\beta} \Rightarrow f\left(x_{\alpha}\right) \geq$ $f\left(x_{\beta}\right)$ with their respective universal quantifiers as the essential features of the definition of the sense of variation.

As seen in the following figure, most of the students are able to make the comparisons, when it was possible, or to determine when it was not possible.

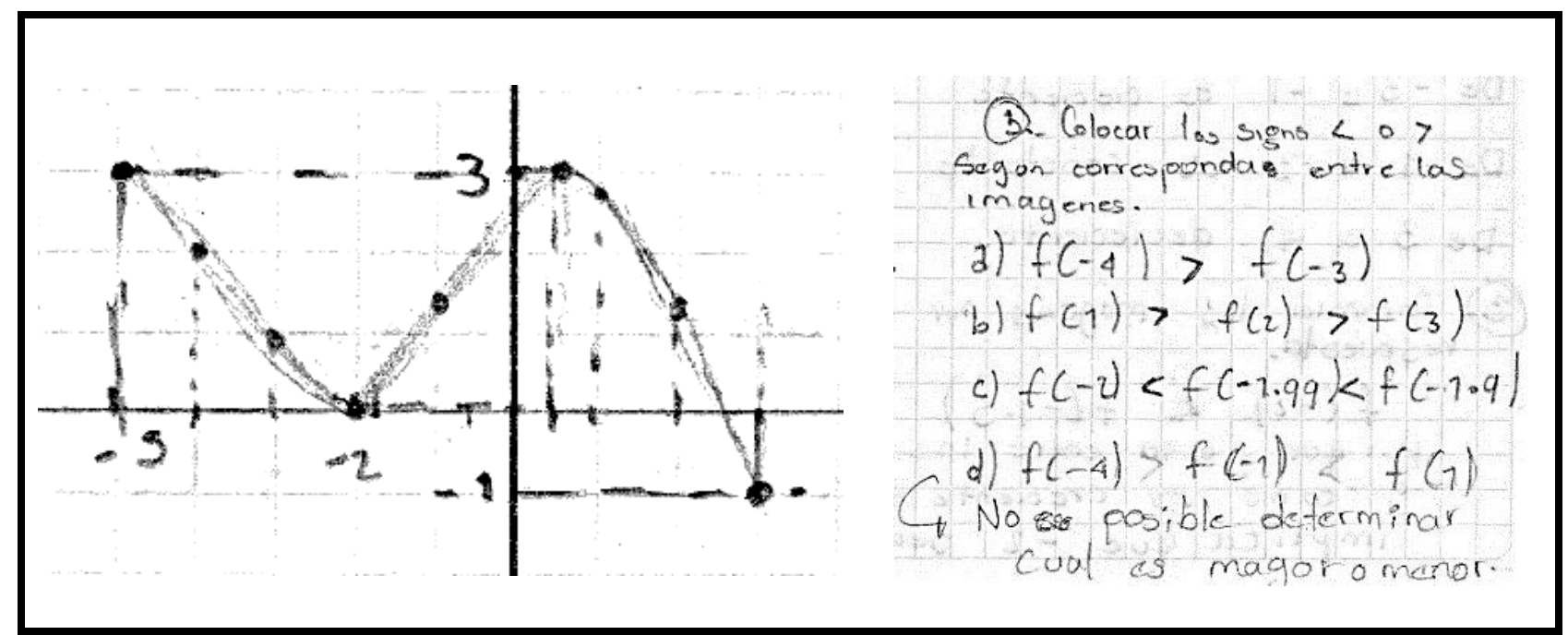

Figure 5. Comparison of the images on the basis of the sense of variation

Conversely, the students had no difficulty in proposing sets of point whose abscissas were in the same order than the ordinates, or sets of points where the abscissas and their respective ordinates were in reverse order from the information of the sense of variation of a function. They chose points in the "increasing zones" for the first case, and points in the "decreasing zones" for the second case; they even draw an oscillating graph for the intervals in which the sense of variation was unknown (Figure 6). 


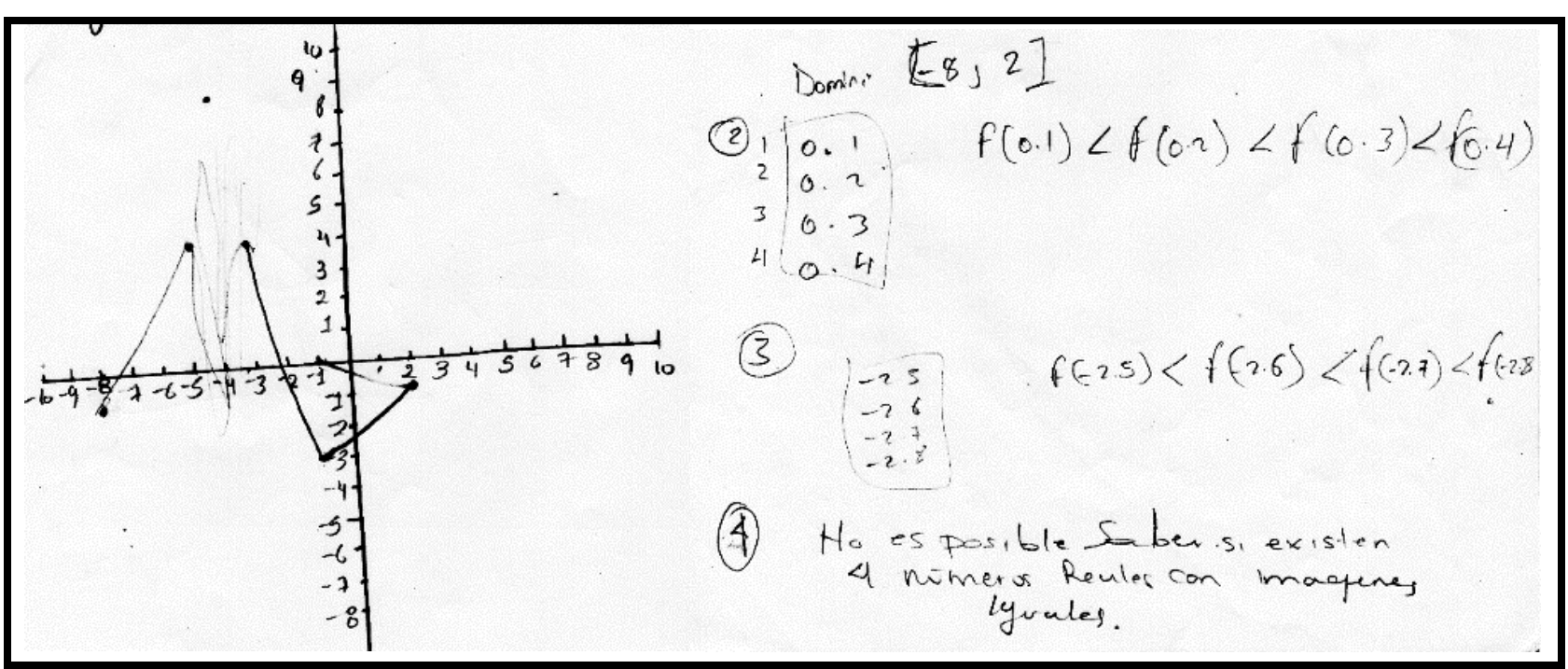

Figure 6. Points proposed by the students from the information of the sense of variation

\section{Institutionalization}

At the end of the expositions of the productions of each team, the TEACHER asked the students to systematize the comparisons between the images of increasing and decreasing functions in a table, and to observe the characteristics carefully.

The debate begins with propositions of the participants on the characteristics observed in these tables and ends with the following participations:

TEACHER: Then, to conclude, what does an increasing function do? Can anyone tell?

S4: When the function decreases, the image is reversed, not the movement of the image.

TEACHER: What is being reversed?

S8: The order of the inequality.

TEACHER: The order. And, when the function is increasing?

S8: The order is preserved.

TEACHER: The order is preserved. If you look, when a function is decreasing, the order is reversed; when the function is increasing, the order is preserved. It is a very important characteristic (Figure 7).

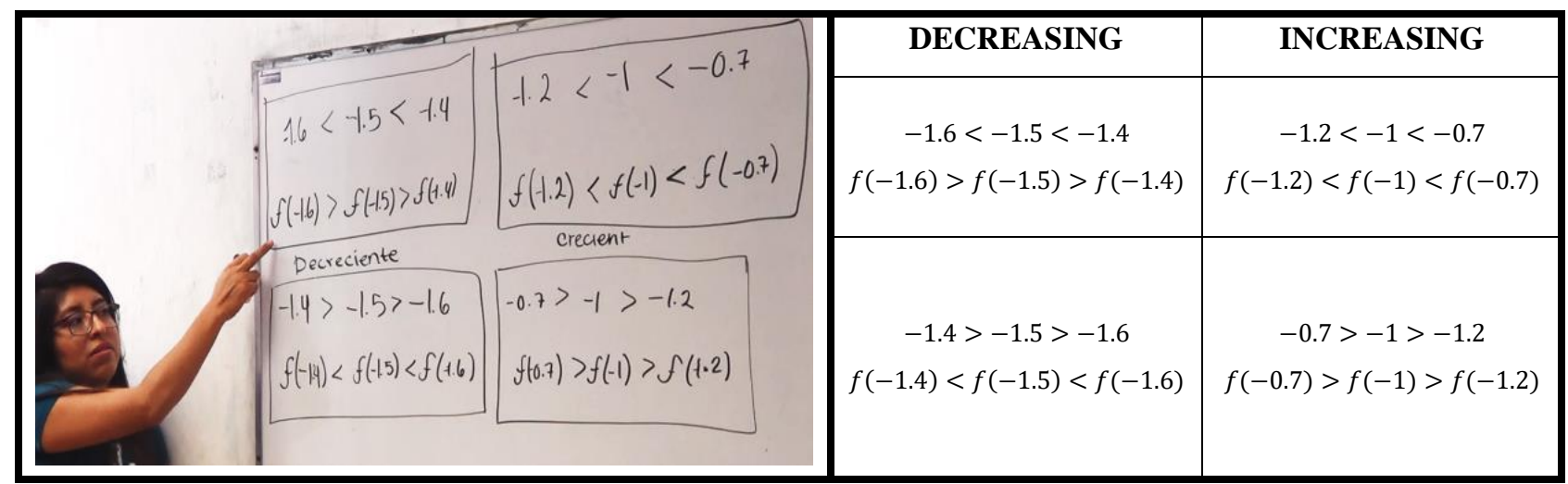

Figure 7.Increasing functions preserve order and decreasing functions reverse order

Later, the scientific debate was directed to break with some ideas observed in the preliminary analyses associated with conceptions such as an increasing function is positive and a decreasing function is negative by using counterexamples. Proposals for definitions involving conditions that guarantee the formal presentation of the definitions of the concepts of increasing and decreasing functions are refuted and developed through the use of counterexamples. The debate on exercise 6 was made in the following terms:

S2: There are no functions that meet these conditions. No function meets them. 
S1: [Draws a Cartesian plane on the interval $[-5,4]$ with an increasing function from -5 to 1 and decreasing from top to bottom until it reaches to 4; this function is defined in pieces] (See Figure 8).

TEACHER: The domain is $[-5,4]$, in this case it is increasing and negative in $[-5,1]$. [Points out Figure 8, moving his hand following this representation]

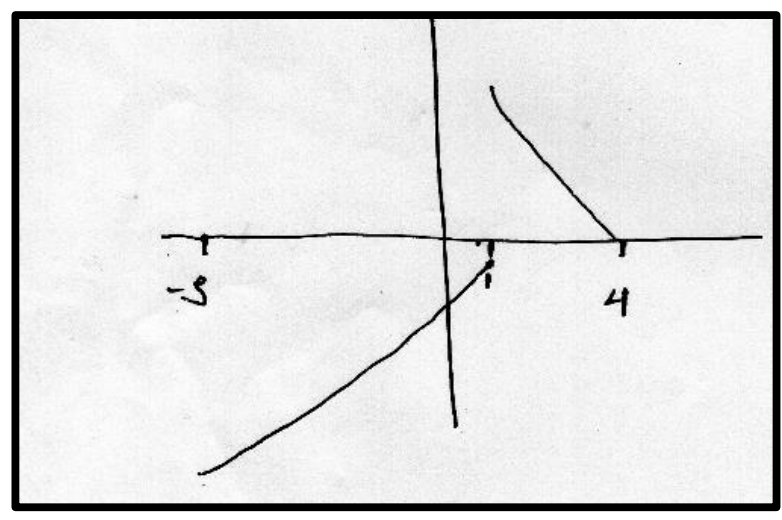

Figure 8. Counterexample of $\mathrm{S} 1$

The graph observed in Figure 8, allows the TEACHER and the students to reflect together on the reasons to obtain this representation and the conditions needed to represent it in this way.

In this reflection, the TEACHER and the students agreed that the conception of associating an increasing function with being positive, and a decreasing function with being negative is an erroneous conception that was necessary to remove.

Finally, with respect to exercise 7, the debate was oriented to understand if it is possible or not to determine the sense of variation of a function when it is known how to compare "a large number of images". This led to the need to quantify the statements. Most of the teams concluded that the function in subparagraph (a) was increasing, and the function in subparagraph (b) was decreasing. The debate began with the figure of S1 in the blackboard:

S1: [Draws a Cartesian plane whose domain is in $[-5,5]$ with a decreasing curve that moves from the second quadrant to the first one, and writes the answer to the question]

TEACHER: Who got something different? [Stands in front of the group]

TEACHER: Does anyone agree with this? [Points out the graphs of S1]

Some reply: Yes

TEACHER: Look closely, the information says that $\mathrm{f}(-5) \leq \mathrm{f}(-4.99) \leq \mathrm{f}(-4.98)$, etc., [Reads and points out the question in Activity III, exercise 7, a)].

S8: You're right, the answer is not that subparagraph (a) is increasing, and subparagraph (b) is decreasing. This cannot be the conclusion [He also points out the graphs].

TEACHER: Why not?

S4: Because we have the images, they could be positive or negatives.

TEACHER: No, no.

S4: Well, the function, we don't have it.

[Other ideas emerge from S4 and S5, among others]

TEACHER: No, that's not why, any ideas S8?

S8: Because the interval is linear and continuous, then there is always a number between $f(5)$ and $f \ldots$

TEACHER: Do you notice what's going on? How could the graph of a function of that nature be? Of that nature you have already imagined? A monster! [Gives the marker to S8 and invites him to draw the figure on the board]

TEACHER: How could it be? Let's see, draw that monster [Motivates S8 to write this idea].

TEACHER: It is subparagraph (a) $\mathrm{f}(-5) \leq \mathrm{f}(-4.99)$. There it is, if you look careful, the points are too close, well, what we considered close [Emphasizes this statement] 
S8: Well, this is supposed to be $f(-5)$ and this one should be -4.99 [He writes it in the board and points out its image].

TEACHER: Yes, -4.99 [Confirms the value of this image].

S8: Then, this little point should be lower or equal [Points out the image of $f(-5)$ ]

TEACHER: Well, what we know is that $f(-5)$ is lower or equal to -4.99 [Points the image of -5$)$ ].

S8: Then, this point should be here [Locates a point in the place shown by the image].

TEACHER: Or it could be higher or lower [Points out the figure that $\mathrm{S} 8$ is drawing].

S8: But we still have little points between these two little points [Points out other points in the domain between $f(-5)$ and $f(-4.99)$, then I can do this [He draws a curve similar to a "v" between the two points of the image]

TEACHER: Fine.

S8: And I could go on with the others in this way. If it is decreasing, then I can have points that are going down [He draws several curves between each of the points located in the Cartesian plane] (See Figure 9).

TEACHER: If you look carefully, we could not say anything about the sense of variation of the function from this information, because we ignore what may happen between one point and the other.

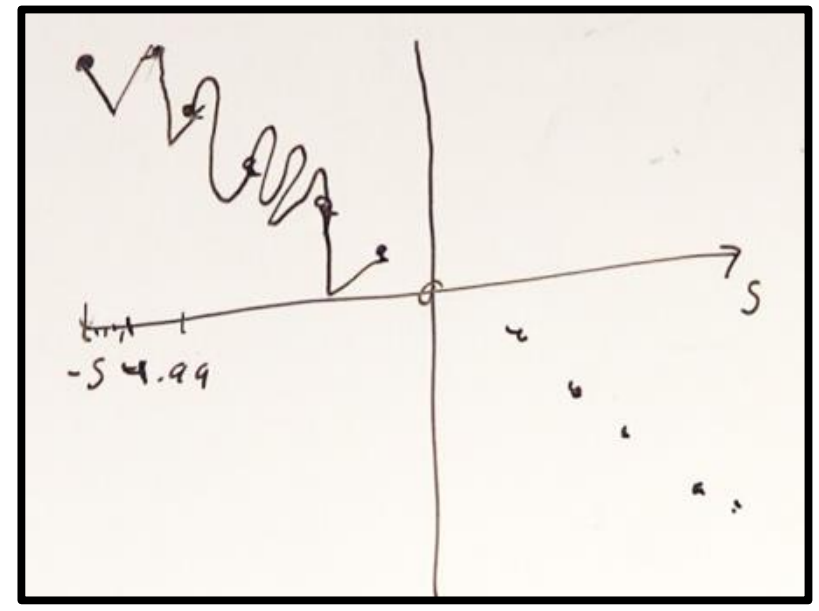

Figure 9. Graph of the counterexample of question 7

The implementation of this phase highlights the following:

Two of the teams involved in the debate managed to solve exercises 1, 2, 3 and 5 of activity III; those exercises are directly linked to the conditions that guarantee the growth and decrease.

\section{EMERGED DEFINITIONS}

The TEACHER directed the activity towards the search for approaches to the definition of increasing and decreasing functions. The following proposals emerged during this process:

Definition 1 (First approach). Increasing function: taking values of the domain, their image will be greater than the value of the domain. The language of this definition is not clear, and it is also very far from the formal definition of an increasing function.

Definition 2 (Second approach). A function is increasing when it starts from a point and the intervals are increasing. This means that " $x$ " and " $y$ " will be increasing and that gives the form of a parabola. This definition is similar to the previous one, but it explicitly talks about increases and increments in the independent and dependent variables. This expression serves as a starting approach towards the formal definition.

Definition 3 (Third approach). A function is increasing when $x$ takes a small value and when the value of $x$ increases, no matter if the function is a straight line or a curve, it will be increasing more and more. This definition could be classified within the dynamic definition (described earlier), but it is also in the narrative terms according to Chorlay (2007). (see Table 3, evolution 1).

Definition 4 (Fourth approach). An increasing function exists when for every increment in " $x$ ", there is an increment in " $y$ ". This is the definition that appears in textbooks (Contreras, 2014; Cuéllar, 2007; Garza, 2015, Sántalo \& Carbonell, 2007), and is given in intuitive terms. However, more than a proper definition it is an informal expression or explanation of the ideas of growth and decrement according to the intuitive idea of dynamic variation of functions. This definition will evolve if the mathematization of the expressions "increment in $x$ " and "increment in $y$ " is achieved, but this implies a change of conception of the sense of variation. 
Definition 5 (Fifth approach). A function is said to be increasing when $x_{1}>x_{2}$ and $f\left(x_{1}\right)>f\left(x_{2}\right)$. The language used in this definition is more precise. It is evident that this definition is not, in strict terms, the exact definition of an increasing function. However, it is a definition that could develop into a more precise form of the formal definition of an increasing function (Osgood, 1912 ) in the institutionalization phase (see Table 3, evolution 2).

Table 2. Identification of the definitions and the consideration of its refutation or evolution

\begin{tabular}{|c|c|c|}
\hline Definitions & The answer is refuted & Evolution \\
\hline Definition 1 & Yes & No \\
\hline Definition 2 & Yes & No \\
\hline Definition 3 & Yes & No \\
\hline Definition 4 & Yes & Yes \\
\hline Definition 5 & Yes & Yes \\
\hline
\end{tabular}

\section{MOVING TOWARDS A FORMAL DEFINITION}

It can be seen from the former definitions of increasing and decreasing functions that two approaches developed towards the formal definition (Table 3):

Table 3. Development of the formal definition of an increasing function

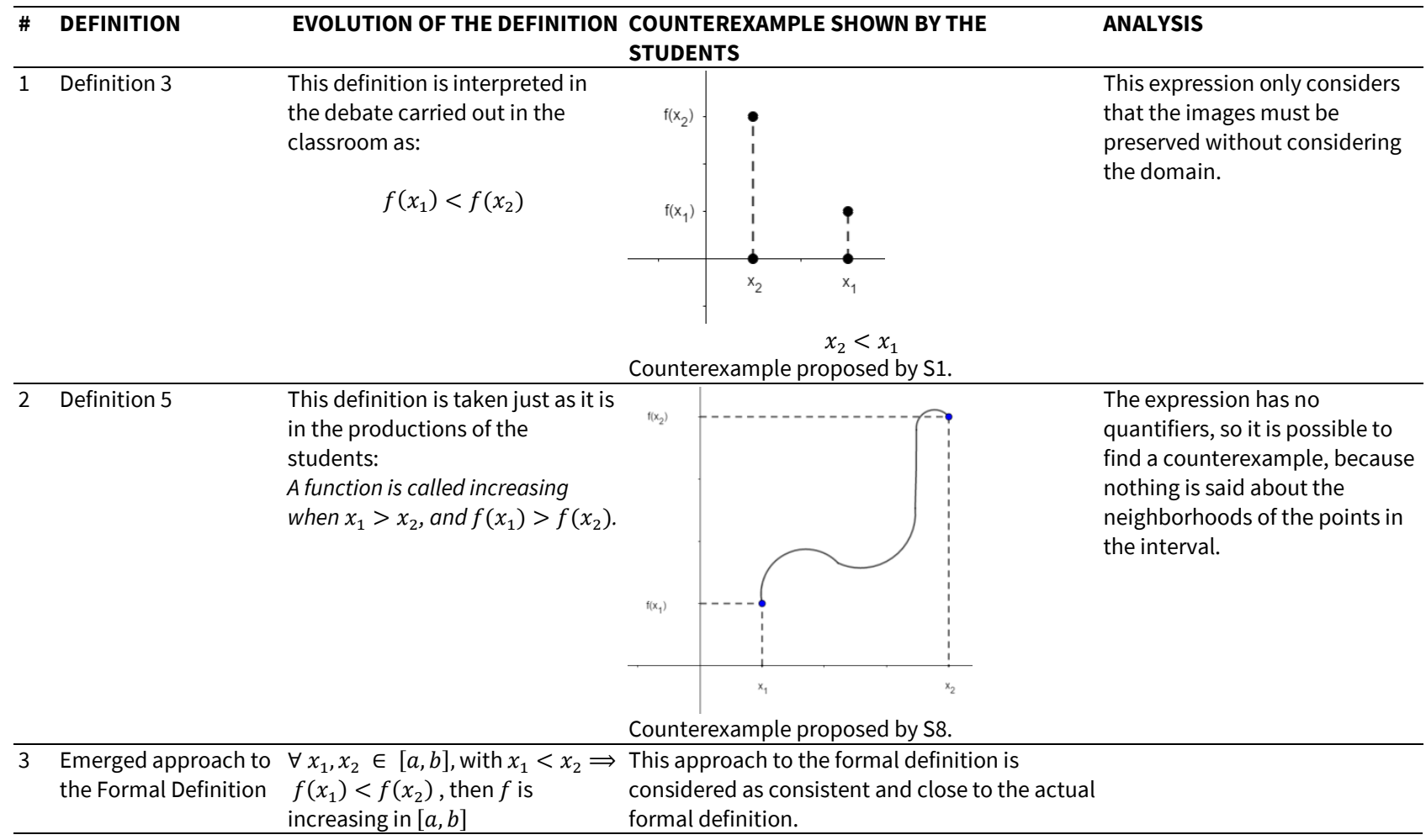

The following analysis comes from Table 3: The formulation of definition 3 lacks of the universal quantifier that declares the variable of the domain and the relationship between them with the implication on its images. Therefore, a counterexample exists; the one proposed by S1 does not allow a closer approach to the formal definition.

A new definition is considered after observing this situation. Definition 5, shown as the evolution 2 in Table 3, is selected for this purpose. The students identified mistakes caused by the lack of universal quantifiers in this new definition of an increasing function, making it harder to determine the variation of a function in an interval, so it was not difficult to find a counterexample that makes this inconsistency evident. S8 proposed the counterexample 2 shown in Table 3 , he was the one who proposed the counterexample of activity III shown in Figure 8.

Finally, definition 2 was refuted with the counterexample 2 shown in Table 3. The analysis of this definition caused its development to a new definition, shown in the same table as definition 3. This new definition is closer to the actual formal definition, and no counterexample may be added; therefore, this definition is considered as valid for all increasing functions. A similar analysis could take place to develop definitions of decreasing functions towards the formal presentation of its definition.

\section{CONCLUSIONS}

The DE carried out with pre-university students showed that the processes of construction of the concepts of increasing and decreasing functions was favored by the use of the scientific debate and the counterexamples used in the activities of 
experimentation and the institutionalization phase. Most of the productions of the students expressed purely intuitive ideas; however, the scientific debate brings these ideas closer to the conditions involved in the formal definitions.

It was considered essential to identify the reading level and the interpretation of the graphs that involved these concepts of increment and decrease by the students who formed the target population. The interpretations made by the students showed that the dynamic notion of increasing and decreasing functions prevails in this population. The dynamic notion favored the treatment of the variation phenomenon in activity II. This activity developed the argumentation of the identification and interpretation of the sense of variation of the functions that represented the areas of the isosceles triangle and the square. It is worth noting that four teams managed to construct the mathematical models, and therefore to plot the geometric place associated with each variation situation. The interpretation of the geometric place identified justifications closer to the formal definition of increasing and decreasing functions.

The treatment of activity III encouraged the students in the identification of the conditions that allow a function to increase or decrease in their given domains and in the development of approaches up to the formal aspect of the classical presentation of their definitions.

The mathematical and methodological preparation of the TEACHER in the didactic, cognitive and epistemological aspects of the mathematical content of the sense of variation of functions was a fundamental factor in the construction of the definition of an increasing function made by the students through the debate and the use of counterexamples.

This work contributes with a teaching-learning proposal of the concepts of increasing and decreasing functions at preuniversity level. This contribution breaks with the classical presentation of the content and highlights the fact that the scientific debate and a proper use of counterexamples as a didactic mediating tool contributes to give meaning to the processes that lead to the formulation of mathematical definitions, as in the case of the concepts studied. Other concepts that are part of the sense of variation of a function, like the maximum and minimum, could be treated under this approach because, from the point of view of the authors, the methodological and mathematical conditions have been prepared for this treatment.

\section{REFERENCES}

Ampère, A. M. (1824). Précis des leçons sur le calcul différentiel et le calcul intégral, CRH cours: A3a 174, Palaiseau, Archives de l'École polytechnique. P. 12. https://doi.org/10.1017/CBO9780511702624.003

Artigue, M. (1995). Ingeniería Didáctica. In M. Artigue, R. Douady, I Moreno, \& P. Gómez (Eds.) Ingeniería Didáctica en Educación Matemática (pp. 33-59). Bogotá, Colombia: Grupo Editorial Iberoamérica.

Ayres, F. (1967). Cálculo diferencial e integral. México: Mc Graw Hill.

Brousseau, G. (1978). "La cours a 20". In Theorie des situations didactiques (1998) La Pensee Sauvage, pp. 24-43. In Etude locale des processus d'acquisition en situation scolaire, Etude sur l'enseignement elementaire (Cuaderno 18,7-21). Bordeaux, IREM y Universidad de Bordeaux 1. https://doi.org/10.7202/012669ar

Cabañas-Ramírez, N., Locia-Espinoza, E., \& Morales-Carballo, A. (2020). Didactic Engineering in the Study of the Sense of Variation of Functions: Preliminary Analysis. International Electronic Journal of Mathematics Education, 15(2), em0566. https://doi.org/10.29333/iejme/6261

Castillo, M. (2009). Un estudio de concepciones del concepto de función en estudiantes de ingeniería. Acta Latinoamericana de Matemática Educativa, 22, 419-427.

Cauchy, A. (1823). Resumé des lecons données à l'École Royale Polytechnique sur le calcul infinitésimal. 1ere partie Analyse Algebraique. Paris, Francia: L'Imprimerie Royale, Debure frères, Libraires du Roi et de la Bibliothèque du Roi. https://doi.org/10.1017/cbo9780511702624.003

Chorlay, R. (2007). La multiplicité des points de vue en Analyse elementaire comme construit historique. In E. Barbin \& D. Bénard (Eds). Histoire et enseignement des mathématiques: erreurs, rigueurs, raisonnements, Lyon: INRP. 203-227.

Contreras, S. (2014). Cálculo Diferencial. México: Fondo de cultura económica.

Cuéllar, J. (2007). Matemáticas V. Cálculo Diferencial. México: Mc Graw Hill.

Cuevas, C., \& Delgado, M. (2016). ¿Por qué el concepto de función genera dificultad en el estudiante? ReCalc, 7, 108-119.

Delgado, M. (2013). Un problema con la concepción de la continuidad de una función. El Cálculo y su Enseñanza, 4, $27-44$.

Díaz, M. (2009). Conocimientos de los profesores preuniversitarios de Cálculo acerca del significado y las interpretaciones de la derivada. El Cálculo y su Enseñanza, 1, 75-90.

Engler, A., Vrancken, S., Gregorini, M., Müller, D., Hecklein, M., \& Henzenn, N. (2008). Estudio del comportamiento de la función a partir de la derivada. Análisis de una secuencia didáctica. Acta Latinoamericana de Matemática Educativa, 21, 466-476. https://doi.org/10.18845/rdmei.v15i1.1992

García, O., \& Morales, L. (2013). Ideas para enseñar: El Contraejemplo como Recurso Didáctico en la Enseñanza del Cálculo. Revista Iberoamericana de Educación Matemática, 35, 161-175. https://doi.org/10.7203/eari.9.11473

Garza, B. (2015). Cálculo diferencial. México: Pearson

Granville, W. A. (2007). Cálculo diferencial e integral. México: Limusa. 
Hernández, J., Locia, E., Morales, A., \& Sigarreta, J. (2019). El contraejemplo en la elaboración de la definición de función convexa por estudiantes universitarios. Información Tecnológica, 30(1). https://doi.org/10.4067/s0718-07642019000100185

Klymchuk, S. (2012). Counterexamples in calculus. Mathematics teaching-research journal, 5(4), 1-30.

Lagrange, L. (1797). Théorie des fonctions analytiques contenant les principes du calcul différentiel dégages de toute considération d'infiniment petits ou de'évanouissans, de limites ou de fluxions et réduits à l'analyse algébrique des quantités finies. En el $9^{\circ}$ cuaderno del Journal de l'École Polytecnique. Paris: République. https://doi.org/10.1017/cbo9780511702730.024

Lakatos, I. (1976). Proofs and Refutations: The Logical of Mathematical Discovery. Cambridge: Cambridge University Press.

Legrand, M. (1993). Débat Scientifique en Cours de Mathématiques et Specifité de L'analyse, Repères IREM, 10, 123-159.

Leithold, L. (1992). El cálculo con Geometría Analítica. México: Harla.

Morales, A., Locia, E., Ramírez, M., Sigarreta, J., \& Mederos, O. (2018). The Theoretical didactic approach to the counterexample in mathematics. International Journal of Research in Education Methodology, 9, $1510-1517$. https://doi.org/10.24297/ijrem.v9i1.8013

Osgood, W. F. (1912). Lehrbuch der Funktionentheorie. Berlín, Alemania: B. G. Teubner.

Pineda, C. (2013). Una propuesta didáctica para la enseñanza del concepto de la derivada en el último grado de educación secundaria (Master Thesis). Universidad Nacional de Colombia. Bogotá, Colombia.

Piskunov, N. (2018). Cálculo diferencial e integral. México: Limusa.

Rey Cabrera, M. (2016). Propuesta didáctica para la formación del profesorado: el caso de la derivada como herramienta de modelización matemática (Master Thesis). Cinvestav, México. https://doi.org/10.30827/profesorado.v22i2.7735

Reséndiz, E. (2006). La variación en las explicaciones de los profesores en situación escolar. Revista Latinoamericana de Investigación en Matemática Educativa, 9(3), 435-458. https://doi.org/10.12802/relime.13.1933

Rubí, G., Moreno, M., Pou, S., \& Jordán, A. (2010). Problemática persistente en el aprendizaje de Cálculo: Caso de la Facultad de Ciencias, UABC. El Cálculo y su enseñanza, 2, 1-10. https://doi.org/10.15517/revedu.v37i1.10627

Ruiz, E., Hernández, J., \& Gutiérrez, J. (2015). Aplicaciones en dispositivos móviles enfocadas al estudio de conceptos de cálculo. El cálculo y su enseñanza, 6, 123-144.

Salinas, P., \& Alanís, J. A. (2009). Hacia un nuevo paradigma en la enseñanza del cálculo dentro de una institución educativa. Revista Latinoamericana de Investigación En Matemática Educativa, 12(3), 355-382. https://doi.org/10.12802/relime13.1910

Sántalo, M., \& Carbonell, V. (2007). Cálculo diferencial. México: Diana.

Stewart, J. (2007). Cálculo Diferencial e Integral. EEUU: Thomson.

Swokowski, E. (1982). Cálculo con Geometría Analítica. EEUU: Wadsworth Internacional Iberoamérica.

Valero, S. (2003). Estabilidad y cambio de concepciones alternativas acerca del análisis de funciones en situación escolar (Doctoral Thesis). CICATA-IPN. México.

Zazkis, R., \& Chernoff, E. (2008). What makes a counterexample exemplary? Educational Studies in Mathematics, 68, $195-208$. https://doi.org/10.1007/s10649-007-9110-4

Zúñiga, M. (2009). Un estudio acerca de la construcción del concepto de función, visualización. en alumnos de un curso de cálculo I (Master Thesis) UPN. Tegucigalpa, Honduras. https://doi.org/10.17013/risti.16.1-16 